REVISTA de

PEDAGOGIE

http://revped.ise.ro

Print ISSN 0034-8678; Online ISSN: 2559 - 639X

\title{
AN INNOVATIVE APPROACH TO ASSESSMENT DURING EARLY EDUCATION
}

O abordare inovativă a evaluării în educația timpurie

\section{Daniela-Mihaela FLORESCU}

Journal of Pedagogy, 2020 (2), 223 - 236

https://doi.org/10.26755/RevPed/2020.2/223

The online version of this article can be found at: http://revped.ise.ro/en/2020/

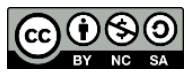

This work is licensed under the Creative Commons Attribution-NonCommercial-ShareAlike 4.0 International License.

To view a copy of this license, visit http://creativecommons.org/licenses/by-nc-sa/4.0/ or send a letter to Creative Commons, PO Box 1866, Mountain View, CA 94042, USA.

Published by:

Centrul NaȚional de Politici și Evaluare ÎN Educație UNITATEA DE CERCETARE ÎN EDUCAȚIE

http://www.ise.ro/

https://rocnee.eu/

Further information about Revista de Pedagogie - Journal of Pedagogy can be found at:

Editorial Policy: http://revped.ise.ro/editorial-policy/

Author Guidelines: http://revped.ise.ro/en/author-guidelines/ 


\title{
O ABORDARE INOVATIVĂ A EVALUĂRII ÎN EDUCA IA TIMPURIE
}

\section{Daniela-Mihaela Florescu*}

\author{
Grădini a cu P.P. „Căsu a Bucuriei” nr. 11, \\ Braşov, România \\ dmflorescu@yahoo.com
}

\section{Rezumat}

IDELA (Dezvoltarea interna ională şi evaluarea timpurie a învă ării) este un instrument de evaluare elaborat în urma unei activită i de trei ani, de către Ivelina Borisova, de la organiza ia Salva i Copiii, cu ajutorul lui Vidur Chopra. Acesta permite să se evalueze dezvoltarea şi educa ia timpurie a copiilor de vârstă mică (3,5-6,5 ani).

Ca urmare a activită ii de verificare şi modificare a instrumentului, de-a lungul unei perioade de trei ani, în mai multe loca ii din 12 ări diferite, a rezultat un instrument de evaluare care include 24 itemi, este uşor de tradus şi gestionat şi prezintă niveluri de fidelitate şi validitate ridicate.

Când s-a aplicat în diferite ări, instrumentul a fost adaptat inând cont de fezabilitatea administrării, de relevan a instrumentului şi a politicii la nivel de ară, precum şi de aplicabilitatea la nivel interna ional.

În România, aplicarea instrumentului a fost realizată în clasa face to face la evaluarea ini ială a 300 de copii cu vârsta de 3-6 ani de la Grădini a „Căsu a Bucuriei”, nr. 11 din Braşov. Dimensiunea inovativă a aplicării a constat în faptul că evaluarea finală s-a realizat într-o ,clasă virtuală”, cu 230 de copii, dar adaptându-ne contextului pandemic în care s-a desfăşurat învă area, fie în scenariu hibrid, fie exclusiv online.

Cuvinte-cheie: clasa face to face, clasa virtuală, educa ia timpurie, evaluare inovativă, instrument interna ional de evaluare.

\section{Abstract}

IDELA (International Development and Early Assessment of Learning) is an

* Director, Grădini a cu P.P. „Căsu a Bucuriei” nr. 11, Braşov, România.

Cadru didactic asociat, Dr., Facultatea de Psihologie şi Ştiin ele Educa iei, Universitatea Transilvania, Braşov, România. 
assessment tool developed following a three-year activity by Ivelina Borisova, from Save the Children, with the help of Vidur Chopra. It allows to evaluate the development and early education of young children (3.5-6.5 years).

The assessment tool resulted after three years of verifying and modifying the instrument, in several locations in 12 different countries. The tool includes 24 items, is easy to translate and manage and presents levels of high fidelity and validity.

When applied in different countries, the instrument has been adapted taking into account the feasibility of administration, the relevance of the instrument and policy at country level, as well as its applicability at international level.

In Romania, the application of the instrument was made face to face during the initial evaluation of 300 children aged 3 -6 at the Kindergarten "Căsu a Bucuriei", no. 11 from Brassov. The innovative dimension of the application was the final assessment: it was conducted in a "virtual classroom" with 230 children, but adapted to the pandemic context in which the learning took place, either in a hybrid scenario or exclusively online.

Keywords: early education, face to face class, innovative assessment, international assessment tool, virtual class.

\section{Contextul cercetării}

Instrumentul IDELA (Dezvoltarea interna ională şi evaluarea timpurie a învă ării), dezvoltat de Funda ia Salva i Copiii, a fost introdus în cadrul de monitorizare şi evaluare a proiectului Pe locuri-fi i gata-start! (engl. ReadySet-Go RSG), implementat de Fondul de Educa ie pentru Romi (REF) România, şi a primit asisten ă tehnică de către Banca Mondială şi sprijin financiar din Granturile norvegiene (Banca Mondială, 2015). Obiectivul vizat a fost de a evalua impactul activită ilor RSG atât asupra dezvoltării copiilor, cât şi asupra mediului de învă are la domiciliu, în familiile care au beneficiat de program.

Aplicarea instrumentului IDELA, în anul 2019-2020, în grădini a noastră, a pornit de la interesul de a demonstra că dezvoltarea copiilor se află în strânsă rela ie cu mediul de învă are şi cu practicile educa ionale, în contexte şi scenarii de învă are foarte diferite (scenariu fa ă în fa ă - septembrie 2019februarie 2020, scenariu roşu - exclusiv online- martie-iunie 2020).

Aceste schimbări ale mediului de învă are (fa ă în fa ă, online sau hibrid) au 
avut impact asupra a tot ceea ce presupune învă area, asigurarea feedbackului, evaluarea, rezultatele copiilor, practicile cadrelor didactice, rela ia cu familiile. În institu iile de învă ământ preşcolar, cadrele didactice s-au adaptat şi au continuat activitatea, dar simpla conversie la con inutul digital nu a fost suficientă.

Curriculumul (MEC, 2019) a fost adaptat noului context de învă are, astfel încât dimensiunile dezvoltării, comportamentele vizate ca aşteptări pentru dezvoltarea la aceste vârste să rămână neschimbate. Con inuturile învă ării au fost flexibilizate şi adaptate în func ie de mediu, de cine acordă suport, pentru că la această vârstă învă area se poate desfăşura doar cu sprijinul şi îndrumarea adul ilor de referin ă - cadrele didactice, respectiv, familia.

Schimbarea a vizat structurarea con inuturilor în stil de prezentare şi adaptarea acestora pentru a se potrivi cu o platformă de livrare. Aceasta a însemnat reorganizarea con inutului, îmbinarea stilurilor didactice de predare, alegerea activită ilor care invită copilul la participarea constantă la activitate în mediul virtual, utilizarea softurilor educa ionale la dispozi ie, a filmelor educative, a înregistrărilor făcute de către profesoare pentru a demonstra şi explica modul de lucru, al testelor şi al jocurilor online sau cu ajutorul altor activită i necesare pentru a creşte implicarea copiilor în procesul de învă are.

Cadrele didactice au trecut prin etapa de a transpune predarea fa ă în fa ă în mediul virtual, al tehnologiei, aceasta fiind considerată mai degrabă o interfa ă utilă în condi iile date.

Treptat, după perioada de încercare a tehnologiei şi de reglare, de adaptare a predării tradi ionale la noile contexte, au început să apară noi direc ii de abordare orientate către extinderea orizontului de con inut, a formelor de organizare a învă ării şi a evaluării. De asemenea, optimizarea designului de învă are în clasa virtuală, a interactivită ii şi implicării copiilor asista i de părin i a continuat să rămână o prioritate.

Experien a noastră a demonstrat că este benefică crearea unui spa iu virtual cu utilizare directă pentru dezbateri, schimburi de informa ii, sesiuni de aplica ii, activită i, jocuri, socializare pentru a men ine legătura cu copiii şi părin ii care au asigurat suport în învă are. 
În perioada stării de urgen ă am creat clasa virtuală prin intermediul platformei Padlet, care oferă numeroase beneficii pentru activită ile de predare, învă are, evaluare. Padlet este o platformă unde profesorii pot crea clase, discuta şi adăuga imagini, fiind multe lucruri care se pot adapta. Spre exemplu, po i face padlet-ul public/privat/protejat cu parola. Cu ajutorul platformei Padlet se poate: să adaugi un hyperlink, o fotografie sau un document (word, pdf), să scrii, să încarci o înregistrare, un film etc. Activită ile pot fi structurate după cum se doreşte (pe tipuri de activită i, pe zile, pe niveluri de vârstă), se poate trimite un singur link părin ilor pentru materialele strânse, structurate şi explicate. Platforma oferă şi alte facilită i: se pot descărca documente în format Word sau Pdf interactiv (cu click pe link-uri); se poate personaliza pagina (poză de fundal, culori diferite pentru fiecare postare, simboluri etc.) şi devine atractivă pentru copii; se acordă feedback imediat şi se pot pune simboluri-recompensă, în scop de apreciere şi motivare, pentru copiii care lucrează şi pentru cei care lucrează bine.

Această aplica ie poate restric iona editarea, lăsând Padlet-ul în modul de vizualizare în perioada când nu te afli la activitate. Ca să deschizi clasa virtuală în Padlet se poate trimite link-ul în multe modalită i: apăsând butonul de distribuire, se poate trimite prin email, Tweet şi alte aplica ii.

Chiar dacă preşcolarii nu s-au mai văzut fizic, învă area, colaborarea, interac iunea socială nu au dispărut, ci au fost încurajate chiar şi în mediul virtual. Interac iunile fizice sunt vitale pentru dezvoltarea abilită ilor de comunicare şi colaborare, dar şi pentru lărgirea orizontului în sfera competen elor, în special ale acelora socio-emo ionale, a capacită ilor şi a atitudinilor în învă are.

S-au desfăşurat activită i distractive, atractive şi interactive, copiii au colaborat şi au experimentat. Prin intermediul acestor activită i, copiii au putut împărtăşi şi beneficia, la rândul lor, de competen ele celorlal i parteneri educa ionali. La momentul actual, există o diversitate de strategii de învă are care ajută la ghidarea şi adaptarea experien elor de învă are şi interac iune socială, chiar şi virtuală.

Organizarea clasei virtuale a fost primul pas asupra căruia ni s-a concentrat aten ia şi a fost urmată de sincronizarea con inutului cu demersurile didactice şi acordarea de sprijin părin ilor, copiii mici având nevoie permanent să fie asista i de adul i. 
Desigur că s-a pus şi problema cum să se realizeze evaluarea la aceste vârste în clasa virtuală. Evaluarea reprezintă un factor cheie al strategiilor/ metodelor de învă are/competen elor (Manolescu, 2015) pentru a asigura un flux continuu în dezvoltarea adecvată a competen elor. Probabil, cel mai mare atu al învă ării în mediul virtual este multitudinea de metode captivante şi interesante de evaluare, cum ar fi jocuri, probe, softuri, precum şi alte instrumente care pot fi aplicate şi fa ă în fa ă.

Evaluarea în clasa online oferă şansa de a identifica acele comportamentele care au nevoie de îmbunătă ire. Rolul formativ al evaluării este dat şi de formularea feedbackului pentru cadrele didactice, dar şi pentru părin i, pentru a vedea ce comportamente, dintre cele vizate, sunt dezvoltate, pentru câte se impune acordarea de sprijin şi care dintre dimensiunile dezvoltării au nevoie de activită i de remediere.

Provocarea a fost şi mai mare în cazul nostru, în condi iile în care evaluarea ini ială am realizat-o utilizând instrumentul IDELA în clasa fa ă în fa ă. Se punea întrebarea dacă, pentru a observa, pe baza acestui instrument rezultatele, progresul copiilor, reuşeam să realizăm o evaluare reală, validă în mediul online. Era important să ne asigurăm că evaluarea putea fi transparentă şi că reflecta adevăratul poten ial al copiilor.

Aplicarea IDELA în evaluarea ini ială şi la evaluarea finală a înlăturat temerile cadrelor didactice fa ă de utilizarea unui format digital pentru evaluare, pe baza unui instrument testat şi aplicat până acum numai în clasele fa ă în fa ă. Astfel, am constatat că rezultatele evaluării au demonstrat progresul copiilor şi au permis părin ilor să fie parte din procesul educa ional şi chiar din cel de evaluare. S-au realizat dialoguri constructive împreună cu copii, iar anumite recomandări ale profesorului (legate de evaluare) au putut fi urmărite şi de către părin i.

Pe viitor, aceste tipuri de evaluare pot fi men inute ca modalită i curente de evaluare. Astfel, percep ia părin ilor fa ă de educa ia timpurie, evaluarea în acest segment şi rela ia lor cu grădini a vor deveni mult mai bune, deoarece vor fi implica i continuu în acest proces. 


\section{Instrumentul de cercetare}

Instrumentul IDELA a fost aplicat în numeroase ări în care popula ia are venituri mici şi medii, cu scopul de a sprijini îmbunătă irea continuă a programului, de a spori responsabilitatea la nivelul ini iativelelor ECCD (engl. Early Childhood Development Initiative) la nivel mondial şi de a oferi date şi dovezi despre rela ia dintre învă are şi dezvoltarea copiilor.

Instrumentul s-a bazat pe o serie de surse şi instrumente existente dintr-un număr de ări unde acestea au fost disponibile, precum şi pe numeroase instrumente dezvoltate şi utilizate de echipele na ionale ale Organiza iei Salva i Copiii. Instrumentul a parcurs mai multe etape de validare: în prima etapă a procesului de validare, peste 65 de itemi au fost testa i cu scopul reducerii numărului acestora şi a identificării itemilor fezabili, care pot fi utiliza i în cât mai multe ări şi contexte, la copiii cu vârste cuprinse între 3-6 ani. Ca urmare a activită ii de verificare şi modificare a instrumentului, de-a lungul unei perioade de trei ani, în mai multe localită i/centre din 12 ări diferite, s-a ob inut un instrument de evaluare care include 24 itemi, care este uşor de tradus şi gestionat şi care prezintă niveluri de fidelitate şi validitate ridicate (IDELA TOOL, 2015, p. 2). În Etiopia, spre exemplu, evaluarea IDELA pentru copii a fost utilizată pentru a măsura învă area timpurie şi dezvoltarea copiilor implica i în program (ELM, 2016).

Rezultatele ob inute prin aplicarea IDELA permit analiza rela iilor dintre dezvoltarea copiilor şi mediile de acasă. Astfel, se constată rela ia direct propor ională între abilită ile mai înalte ale copiilor şi mediul favorabil de învă are la domiciliu (mai multe materiale şi activită i de învă are). De asemenea, pentru toate categoriile incluse în IDELA, copiii din familiile în care veniturile sunt mai mari tind să aibă scoruri de dezvoltare anterioară mai bune în compara ie cu colegii din familii care dispun de mai pu ine resurse financiare, cu excep ia categoriei dezvoltare motorie emergentă (vezi Figura nr. 1). Nu s-au găsit diferen e semnificative între abilită ile timpurii ale băie ilor şi fetelor. Interesant, nu au existat rela ii semnificative între perioada de timp petrecută de copii în centrele ECCD şi abilită i de învă are timpurie.

Având în vedere natura cuprinzătoare a instrumentului, precum şi utilizarea globală extinsă, în contexte diverse (de exemplu, în proiecte care au vizat 
incluziunea romilor în Bulgaria şi Slovacia), IDELA a fost selectat în comun de REF România şi Banca Mondială drept instrumentul principal pentru a evalua impactul activită ii de Ready-Set-Go atât pentru dezvoltarea copiilor, cât şi pentru mediul de învă are la domiciliu în familiile care beneficiază de program.

Aplicarea instrumentului IDELA în cercetarea noastră a avut ca obiectiv evaluarea impactului interven iilor educa ionale realizate în clasa virtuală, atât asupra dezvoltării copiilor, cât şi asupra mediului de învă are la domiciliu, copiii fiind sprijini i de către diferi i membrii ai familiei şi de profesorii care au asumat rolul de facilitatori.

Elementele componentă ale evaluării, incluse în IDELA, sunt incluse în tabelul de mai jos.

\begin{tabular}{|c|c|c|c|c|}
\hline $\begin{array}{c}\text { Brut şi fin } \\
\text { Abilită i motorii }\end{array}$ & $\begin{array}{c}\text { Alfabetizare } \\
\text { emergentă }\end{array}$ & $\begin{array}{c}\text { Alfabetizare } \\
\text { numerară }\end{array}$ & $\begin{array}{c}\text { Dezvoltare socio- } \\
\text { emo ională }\end{array}$ & Al i itemi \\
\hline opăit & În elegerea tipăriturii & Mărime/greutate & Prieteni & $\begin{array}{c}\text { Abordări la } \\
\text { învă are }\end{array}$ \\
\hline Copiază o formă & Vocabular expresiv & Indica ii & $\begin{array}{l}\text { Recunoaştere } \\
\text { emo ii de sine }\end{array}$ & Inhibitor control \\
\hline $\begin{array}{c}\text { Desenează o figură } \\
\text { umană }\end{array}$ & Identificarea scrisorii & Sortare & $\begin{array}{l}\text { Recunoaştere } \\
\text { emo ii în altele }\end{array}$ & Sortează itemi \\
\hline \multirow[t]{5}{*}{ Împachetează hârtia } & Scriere emergentă & $\begin{array}{c}\text { Identificarea } \\
\text { numărului }\end{array}$ & Conflict rezolvat & De memorie \\
\hline & $\begin{array}{c}\text { Conştientizarea } \\
\text { auzului fonematic }\end{array}$ & Identifica formei & Informa ii personale & \\
\hline & În elegere orală & $\begin{array}{c}\text { Coresponden a } \\
\text { unu la unu }\end{array}$ & & \\
\hline & & Opera ii simple & & \\
\hline & & Puzzle complet & & \\
\hline
\end{tabular}

Figura nr. 1. Elementele incluse în IDELA

Înainte de a începe orice evaluare, este important să se stabilească un context relaxat, stimulativ pentru copilul evaluat.

Instrumentul recomandă a se începe evaluarea prin câteva întrebări cu privire la subiecte care îl interesează, astfel încât copilul să perceapă evaluarea ca pe un joc, mai curând, decât ca pe un test serios. 


\section{Aplicarea instrumentului şi interpretarea rezultatelor}

Instrumentul IDELA acoperă toate domeniile de dezvoltare cuprinse în Repere fundamentale în învă area şi dezvoltarea timpurie a copilului, documentul de referin ă pentru monitorizarea şi evaluare achizi iilor copiilor din învă ământul preşcolar. ${ }^{1}$

Având în vedere aceste similitudini, IDELA a fost aplicat în Grădini a „Căsu a Bucuriei”, nr. 11 Braşov, în perioada septembrie - octombrie 2019 pe parcursul a două săptămâni de evaluare ini ială, la toate cele 11 grupe de copii din grădini ă (N=300): patru grupe mari, patru grupe mijlocii şi trei grupe mici; aşadar, în evaluare au fost cuprinşi copii între 3 şi 5-6 ani. Instrumentul a fost aplicat în clasa fa ă în fa ă de către educatoarele grupelor. La grupele mici, perioada de evaluare a fost extinsă până la o lună, prin urmare, aplicarea instrumentului s-a finalizat în săptămâna 24-30 octombrie 2019.

Datele au fost prelucrate şi interpretate de către directorul grădini ei şi de un părinte sociolog.

Acest instrument a fost aplicat încă o dată la finalul semestrului I, în perioada ianuarie 2020, de asemenea, în clasa fa ă în fa ă. Au fost culese datele, interpretate şi comparate cu cele de la evaluarea ini ială.

Evaluarea finală s-a realizat în iunie 2020, dar în clasa virtuală, având în vedere starea de urgen ă. Numărul copiilor evalua i în acel moment a scăzut uşor la 230, fiindcă mul i dintre copii au fost lăsa i în grija bunicilor sau nu au avut acces la internet sau la aparatura specifică activită ii de învă are la distan ă.

Interpretarea datelor s-a făcut în programul SPSS.

Rezultatele ob inute de copii la evaluarea ini ială (din septembrie-octombrie 2019), în clasa fa ă în fa ă şi la evaluarea finală (din iunie 2020), în clasa virtuală sunt redate în tabelul nr. 1. Tabelul include doar rezultatele copiilor care au participat la evaluarea ini ială şi la cea finală.

Rezultatele pun în valoare progresul realizat de către copii, de la evaluarea 
ini ială la cea finală, datorat unui program de interven ie educa ională, într-un mediu de învă are diferit (mediul online).

Tabelul nr. 1. Centralizarea rezultatelor la evaluarea ini ială şi la cea finală

\begin{tabular}{|c|l|c|c|}
\hline $\begin{array}{c}\text { Nr. } \\
\text { Crt. }\end{array}$ & \multicolumn{1}{|c|}{$\begin{array}{c}\text { CATEGORII/ } \\
\text { TERMENI DE REFERIN }\end{array}$} & $\begin{array}{c}\text { EVALUARE } \\
\text { INI IALA } \\
\text { (230 COPII } \\
\text { EVALUA I) }\end{array}$ & $\begin{array}{c}\text { EVALUAREA } \\
\text { FINALĂ } \\
\text { (230 COPII } \\
\text { EVALUA I) }\end{array}$ \\
\hline $\mathbf{1 .}$ & CONŞTIN Ă PERSONALĂ & $4,76 \%$ & $5,35 \%$ \\
\hline $\mathbf{2 .}$ & MĂRIME/LUNGIME & $3,19 \%$ & $3,81 \%$ \\
\hline $\mathbf{3 .}$ & SORTARE/CLASIFICARE & $1,42 \%$ & $1,84 \%$ \\
\hline $\mathbf{4 .}$ & FORME & $3,23 \%$ & $4,32 \%$ \\
\hline $\mathbf{5 .}$ & IDENTIFICARE DE NUMERE & $8,73 \%$ & $11,6 \%$ \\
\hline $\mathbf{6 .}$ & CORESPONDEN A UNU LA UNU & $2,83 \%$ & $3,80 \%$ \\
\hline $\mathbf{7 .}$ & ADUNARE/SCĂDERE & $1,43 \%$ & $2,37 \%$ \\
\hline $\mathbf{8 .}$ & COMPLETARE PUZZLE & $3,66 \%$ & $5,33 \%$ \\
\hline $\mathbf{9 .}$ & PRIETENI & $4,05 \%$ & $7,35 \%$ \\
\hline $\mathbf{1 0 .}$ & CONŞTIIN Ă EMO IONALA & $2,84 \%$ & $3,65 \%$ \\
\hline $\mathbf{1 1 .}$ & EMPATIE & $2,13 \%$ & $2,70 \%$ \\
\hline $\mathbf{1 2 .}$ & SOLU IONAREA CONFLICTELOR & $1,63 \%$ & $2,50 \%$ \\
\hline $\mathbf{1 3 .}$ & MEMORIE DE LUCRU & $2,07 \%$ & $3,15 \%$ \\
\hline $\mathbf{1 4 .}$ & JOCUL CAP/PICIOARE & $6,11 \%$ & $7,63 \%$ \\
\hline $\mathbf{1 5 .}$ & VOCABULAR ORAL & $10,87 \%$ & $12,07 \%$ \\
\hline $\mathbf{1 6 .}$ & CONŞTIENTIZAREA LITERELOR SCRISE & $1,81 \%$ & $2,67 \%$ \\
\hline $\mathbf{1 7 .}$ & IDENTIFICAREA LITERELOR & $4,04 \%$ & $6,31 \%$ \\
\hline $\mathbf{1 8 .}$ & PRIMELE SUNETE/LITERE & $1,27 \%$ & $2,14 \%$ \\
\hline $\mathbf{1 9 .}$ & SCRIERE & $1,47 \%$ & $2,64 \%$ \\
\hline $\mathbf{2 0 .}$ & ÎN ELEGERE VERBALĂ & $5,06 \%$ & $6,33 \%$ \\
\hline $\mathbf{2 1 .}$ & COPIERE DE FORME & $1,53 \%$ & $3,13 \%$ \\
\hline $\mathbf{2 2 .}$ & DESENUL UNEI PERSOANE & $5,72 \%$ & $6,75 \%$ \\
\hline $\mathbf{2 3 .}$ & IMPĂTURIREA HÂRTIEI & $2,79 \%$ & $5,28 \%$ \\
\hline $\mathbf{2 4 .}$ & SĂRITURI & $6,97 \%$ & $8,65 \%$ \\
\hline & & & \\
\hline & & & \\
\hline
\end{tabular}

Pentru a calcula un scor total IDELA, răspunsurile copiilor la fiecare cerin ă inclusă în instrumentul de evaluare sunt adunate şi împăr ite la numărul total de răspunsuri. Altfel spus, rezultatul IDELA este dat de numărul (absolut şi în procente) al copiilor care se încadrează într-una din cele şase categorii de răspuns (de la nici un răspuns până la şase răspunsuri corecte).

În imaginile de mai jos, prezentăm rezultatele ob inute de copii (evaluarea ini ială) la categoria conştiin ă personală. Tabelul prezintă frecven a răspunsurilor copiilor participan i la evaluare, pentru variabila ,conştiin ă personală" şi procentajul înregistrat de fiecare copil raportat la numărul total de subiec i. 


\begin{tabular}{|c|c|c|c|c|c|}
\hline & & Frequency & Percent & Valid Percent & Cumulative Percent \\
\hline \multirow{8}{*}{ Valid } & zero puncte & 2 & ,9 & ,9 & ,9 \\
\hline & un punct & 4 & 1,7 & 1,7 & 2,6 \\
\hline & doua puncte & 20 & 8,7 & 8,7 & 11,3 \\
\hline & trei puncte & 20 & 8,7 & 8,7 & 20,0 \\
\hline & patru puncte & 35 & 15,2 & 15,2 & 35,2 \\
\hline & cinci puncte & 43 & 18,7 & 18,7 & 53,9 \\
\hline & sase punctaj maxim & 106 & 46,1 & 46,1 & 100,0 \\
\hline & Total & 230 & 100,0 & 100,0 & \\
\hline
\end{tabular}

Figura nr. 2. Răspunsurile copiilor la categoria Conştiintă personală (evaluare ini ială)

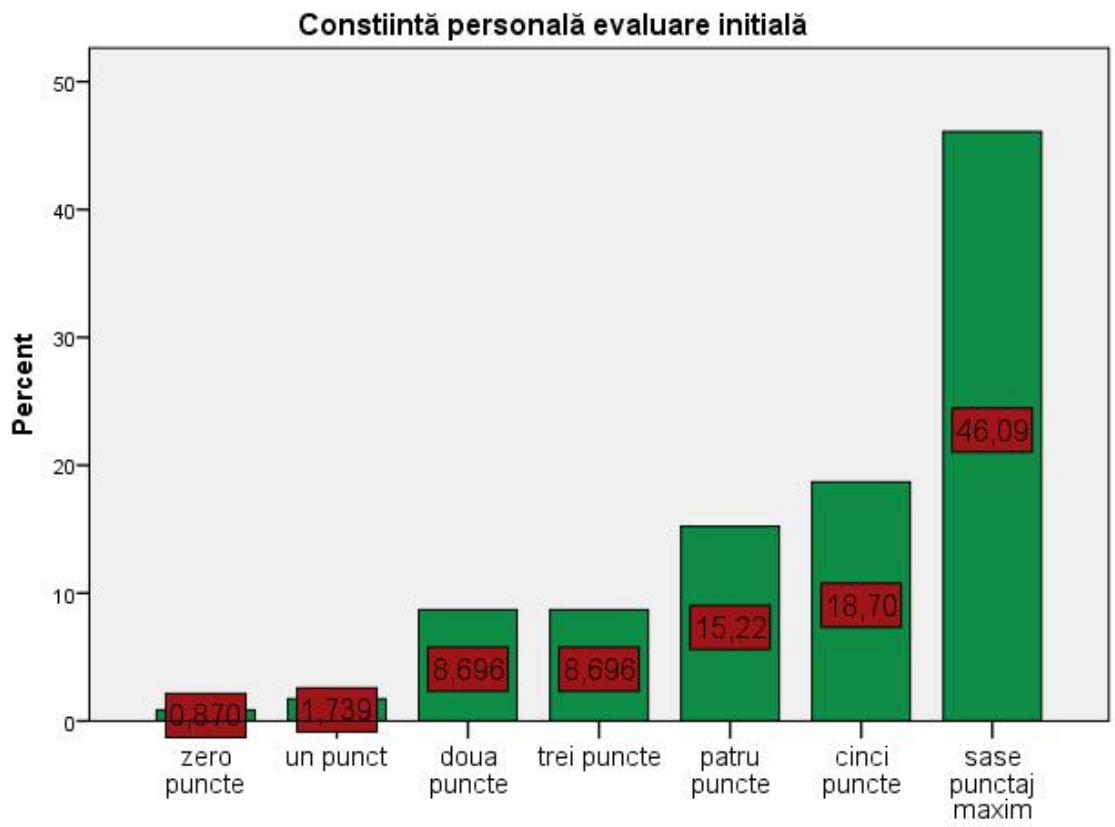

Constiintă personală evaluare initială

Figura nr. 3. Ierarhia punctajului (de la 0 la 6 puncte) la categoria constiin ă personală 


\section{Programul de interven ie bazat pe metoda stimulării optime a creierului (engl. brain friendly manner) şi rezultatele ob inute la evaluarea finală pe baza IDELA}

De la evaluarea ini ială până la evaluarea finală s-a înregistrat un progres în rezultatele copiilor, aşa cum reiese şi din datele prezentate în tabelul nr. 1. Rezultatele sunt explicabile prin faptul că între cele două etape de evaluare, copiii care au frecventat cursurile în perioada stării de urgen ă $(N=230)$ au participat la programul de interven ie pregătit de educatoare având ca punct de plecare noul curriculum pentru educa ie timpurie. ${ }^{2}$ Interven ia a fost fundamentată pe proiectarea con inuturilor pornind de la rezultatele copiilor ob inute în cadrul evaluării ini iale, pentru fiecare item din instrumentul de evaluare.

Activită ile de predare au utilizat metoda stimulării optime a creierului (engl. brain friendly manner). Predarea bazată pe această metodă este aliniată la modul în care creierul func ionează cel mai bine şi anume: să participe, să proceseze, să re ină şi să reactiveze informa ii. Cu ajutorul acestei metode, predarea devine mai veselă, iar învă area este mai distractivă şi mai eficientă (Kagan, 2020). Construind un mediu plin de respect, utilizând cuvinte încurajatoare, feedbackul pozitiv şi rutine familiare, acordăm creierului copilului răgazul de a se relaxa şi de a primi noi informa ii. Emo iile copiilor sunt implicate în învă are şi, atunci când profesorii sau părin ii asigură unui copil o atmosferă de siguran ă, este mai uşor pentru ei să transfere cunoştin ele în memoria lor pe termen lung. Copiilor li s-a oferit ocazia de a participa la activită i care să le ofere o mul ime de oportunită i de a practica noi abilită i. S-au creat activită i antrenante care ocupă nu numai creierul, ci implică şi mişcarea fizică, prin care copiii înva ă şi mai mult. Folosind activită i care permit copiilor să manipuleze obiecte şi să utilizeze imagini ca instrumente de învă are, i-am ajutat îşi concentreze aten ia asupra sarcinii de lucru.

Datele adunate pe parcursul evaluării sugerează că materialele de lectură şi activită ile de lectură la domiciliu, sub îndrumarea familiei, anticipează semnificativ scorurile legate de litera ie, în timp ce numărul de jucării disponibile anticipează scoruri legate de numera ie. Situa ia descrisă implică faptul că adaptarea activită ilor de interven ie s-ar putea baza pe punerea la 
dispozi ie a materialelor de citire şi a jucăriilor pentru copiii şi familiile participante, precum şi pe încurajarea continuă a activită ilor de lectură cu copilul.

Toate activită ile bazate pe metoda stimulării optime a creierului au condus la rezultate mai bune la evaluarea finală, prin scorurile ob inute la evaluarea finală (vezi tabelul nr. 1). Astfel, programul de interven ie pare a oferi o cale promi ătoare către progresul în învă are, indiferent de mediul în care se desfăşoară învă area.

\section{Concluzii}

Aplicarea instrumentului IDELA în etapa de evaluare finală a eviden iat o creştere a scorurilor la majoritatea domeniilor evaluate prin acest instrument, pentru to i copiii participan i la cele două etape de evaluare. Deşi datele nu sunt relevante statistic, din cauza dimensiunii eşantionului, ele permit totuşi formularea unor aprecieri referitoare la progresul copiilor participan i la programul de interven ie bazat pe metoda stimulării optime a creierului.

Rezultatele finale sunt cu atât mai relevante cu cât sunt asociate unor activită i de învă are desfăşurate la distan ă. Astfel, prin aceste rezultate este validat nu doar programul de interven ie, dar şi aplicarea online a instrumentului. Pe baza continuării proiectului în anul şcolar 2020-2021, folosind un eşantion mai mare, există premise pentru extinderea programului, în parteneriat cu organiza ia Salva i copiii, la mai multe grădini e din oraşul Braşov. Printre beneficiile acestuia men ionăm încurajarea bunelor practici parentale, prin implicarea continuă a părin ilor în procesul de învă are şi evaluare.

Prin participarea la programul de interven ie, cadrele didactice au conştientizat cum se lucrează cu instrumentul IDELA, inclusiv în mediul virtual. Ele au lucrat intens cu familiile copiilor, trimi ând materiale suport, unde a fost cazul, pentru a veni în sprijinul părin ilor. De asemenea, au conştientizat că pot acorda o mai mare aten ie individualizării, centrării pe copil, pe parcursul evaluării online şi au avut ocazia de a-şi extinde şi perfec iona practicile de evaluare, mai ales în privin a oferirii şi primirii de feedback. Participarea cadrelor didactice la programul de interven ie a însemnat o ocazie de dezvoltare 